\title{
An evaluation of boreal summer intra-seasonal oscillation simulated by BCC_AGCM2.2
}

\author{
Yongjie Fang ${ }^{1} \cdot$ Peili $\mathrm{Wu}^{2} \cdot$ Tongwen Wu $^{1} \cdot$ Zaizhi Wang $^{1} \cdot \mathrm{Li} \mathrm{Zhang}^{1} \cdot \mathrm{Xiangwen} \mathrm{Liu}^{1}$ \\ Xiaoge Xin ${ }^{1} \cdot$ Anning Huang ${ }^{3}$
}

Received: 8 September 2015 / Accepted: 14 July 2016 / Published online: 22 July 2016

(C) The Author(s) 2016. This article is published with open access at Springerlink.com

\begin{abstract}
The intra-seasonal oscillation (ISO) is a prominent feature of the East Asia summer monsoon. The Beijing Climate Center model is one of the IPCC models participating in the Coupled Model Inter-comparison Project (CMIP) 3 and CMIP5 experiments. This paper presents a systematic evaluation of ISO simulated by the Beijing Climate Center atmospheric general circulation model version 2.2 against observations. The model reasonably simulates some salient features of BSISO in terms of temporal spectrum, leading EOF modes, and vertical structure, however limitations are also evident. The strength of the BSISO is overestimated and the northward propagating rain belt is tilted southwest-northeast, which is also different from the observation. The model tends to produce unrealistically strong but shallow convection associated with the ISO, leading to a northward shift of the Western Pacific Subtropical High and the main rain band compared to observations. Process studies show that the anomalous convective heating associated with the wet model bias drives a Gill-type response, resulting in the northwesterly biased position of Western Pacific Subtropical High. The study has revealed how the interaction of moist processes and large-scale dynamics can lead to model bias in simulating the east Asian regional climate system and its variability (ISO in particular). Future improvements in model resolution and convection parameterization are expected to reduce such errors.
\end{abstract}

Peili Wu

peili.wu@metoffice.gov.uk

1 Beijing Climate Center, China Meteorological Administration, Beijing, China

2 Met Office Hadley Centre, Exeter, UK

3 School of Atmospheric Sciences, Nanjing University, Nanjing, China
Keywords East Asia summer monsoon · Intra-seasonal oscillation $\cdot$ Climate model evaluation $\cdot$ BCC climate model

\section{Introduction}

The intra-seasonal oscillation (ISO) is regarded as a dominant mode of variability of the East Asia (EA)-western North Pacific (WNP) summer monsoon. Unlike the eastward propagating Madden-Julian Oscillation (Madden and Julian 1972) in winter, the boreal summer ISO (BSISO), with a periodicity of $10-90$ days, is characterized by a pronounced northward or northwestward propagation over the EA-WNP region (Lau and Chan 1986; Wu and Li 1990; Hsu and Weng 2001). The northward propagation of the ISO manifests in the active and break spells of EA-WNP summer monsoon and influences precipitation associated with the northward advance of Meiyu (central China)-Baiu (Japan) front, which is related to the onset of the summer rainy season. The ISO over the WNP region can modulate the subtropical high and typhoon activities. It, therefore, has a significant socio-economic impact on many East Asian Countries (Chen and Murakami 1988; Wang and Xie 1997; Shukla 2014). Due to its quasi-periodic occurrence, the BSISO provides optimism for extended range prediction of the EA-WNP summer monsoon on sub-seasonal time scales (Li and Wu 1990; Wu 1993).

Realistic simulation and prediction of the complexity of the ISO over the Asian summer monsoon region remain a serious challenge for current general circulation models (GCMs) (Yang et al. 2009; Sabeerali et al. 2013; Zhao et al. 2014). Most of the models simulate too strong local persistence of equatorial rainfall and too weak northward-propagating ISO rainfall signal (Lin et al. 2006; Hu et al. 2013). 
Waliser et al. (2003) found that most of the atmospheric GCMs (AGCMs) show some form of meridional propagation of BSISO over the equatorial Indian Ocean region, but the model ISO patterns are typically less coherent and have smaller zonal and meridional spatial scales than the observed patterns. Lin et al. (2008) evaluated BSISO over the Asian monsoon region in $14 \mathrm{GCMs}$ and found that most of them overestimate the near-equatorial precipitation and underestimate the variability of the northward propagating BSISO. Sperber and Annamalai (2008) have shown that only a few of the CMIP3 (Coupled Model Intercomparison Project phase 3) models manage to produce statistically significant anomalies that comprise the northwest to southeast tilted convection associated with the BSISO. They emphasize the importance of correctly simulating the seasonal mean state of precipitation and SST on the BSISO simulation. Sabeerali et al. (2013) have recently analyzed the historical runs of 32 CMIP5 models. They have found that, compared to CMIP3 models, more CMIP5 models are able to produce the northward propagation of BSISO. However, most models still cannot properly simulate the spatial pattern of BSISO variance over the Asian monsoon region and fail to simulate the phase-relationship between the ISO-related precipitation and winds, which is observed with easterly (westerly) anomalies leading (lagging) the enhanced convection anomaly.

Although the exact reason is not clear, it is generally believed that inadequate representation and description of moisture processes and the associated scale interactions are likely the major culprit (Fu et al. 2006; Sooraj and Seo 2013; Demott et al. 2014). Some recent studies have suggested that interactions between different cloud regimes, circulation, and diabatic heating in the boundary layer may play a critical role for the evolution of the BSISO (Chattopadhyay et al. 2009; Jiang et al. 2011; Abhik et al. 2013). The role of deficiencies in relation to background states in influencing the northward propagating BSISOs has also been suggested by many studies (Jiang and Li 2005; Ajayamohan and Goswami 2007; Seo et al. 2007; Sabeerali et al. 2013).

In the present paper, we present an evaluation of the ISO of the EA-WNP summer monsoon in the Beijing Climate Center atmospheric general circulation model version 2.2 (BCC_AGCM2.2), which is the atmospheric component of the Short-range Operational Climate Prediction System of China National Climate Center. A new mass-flux cumulus parameterization scheme, which includes more sophisticated cloud processes and vertically variable entrainment, was introduced and the model shows improved simulation of deep convection and the associated vertical heating profile (Wu 2012). Given the important role of the model convective parameterization in the realism of ISO simulations
(Seo et al. 2007; Benedict et al. 2013), evaluation of the model performance and identification of biases and their possible sources in BSISO simulation over the EA-WNP region would provide us much needed guidance for further improvement of the model.

Section 2 presents detailed model description, observational dataset utilized for the evaluation and methodologies of analysis. The model's basic state and BSISO characteristics are described in Sect. 3. The major conclusions and discussions are summarized in Sect. 4.

\section{The model, observation data and methodology}

\subsection{BCC_AGCM2.2 model and experiments}

BCC_AGCM2.2 is the atmospheric component of the latest version of the BCC climate model with a horizontal resolution of T106, approximately $1.1^{\circ} \times 1.1^{\circ}$. It uses a terrainfollowing hybrid vertical coordinate including 26 vertical layers with the top layer at $2.9 \mathrm{hPa}$. BCC_AGCM2.2 is based on the Community Atmosphere Model Version 3 (CAM3) developed by the National Center for Atmospheric Research. The dynamic core is modified by introducing a reference temperature and a reference surface pressure into the governing equations (Wu et al. 2008). Other major modification to the model physics includes a new convective parameterization scheme, a dry adiabatic adjustment scheme in which potential temperature is conserved, a modified scheme to calculate the sensible heat and moisture fluxes over the open ocean that takes into account the effect of ocean waves on the latent and sensible heat fluxes, and an empirical equation to compute the snow cover fraction (Wu and $\mathrm{Wu}$ 2004). The model provides overall improvements to climate simulations in comparison to CAM3, especially for simulating the tropical maxima/subtropical minima of precipitation, wind stress, and sensible and latent heat fluxes at the ocean surface (Wu et al. 2010; Kan et al. 2015). A detailed description of BCC_AGCM can be found in Wu et al. (2010) and Wu (2012).

The simulations analyzed in this study is a five-member ensemble using BCC_AGCM2.2 forced with observed sea surface temperature (SST) and sea ice concentrations for the period 1996-2011, taken from the global Hadley Center Sea Ice and Sea Surface Temperature (HadISST) dataset (Rayner et al. 2003). Greenhouse gas concentrations are held constant at the 1990 level. Aerosol forcings are included using a monthly mean climatology of sulfate, sea salt, carbonaceous, and soil-dust aerosols (Collins et al. 2006). Each ensemble member with different initial conditions is run for 15 years but only the last 10 years are used for the ensemble mean analyzed below. 
(a) $\operatorname{TRMM}(\mathrm{ERAI})$

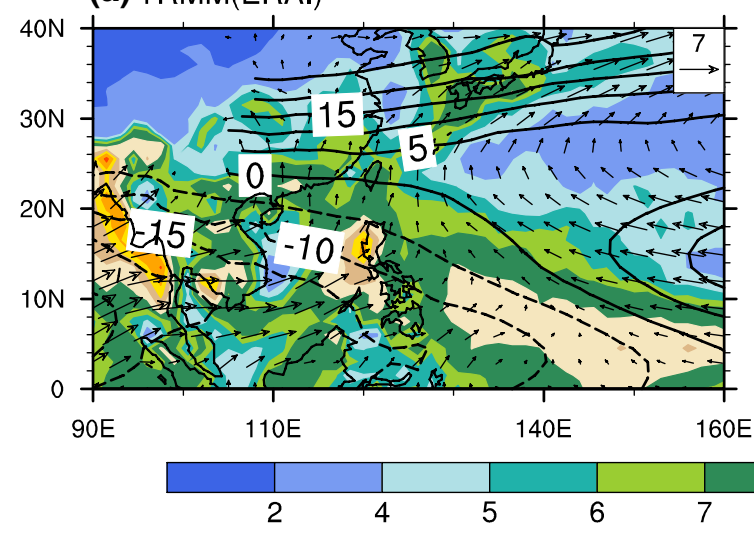

(b) BCC AGCM

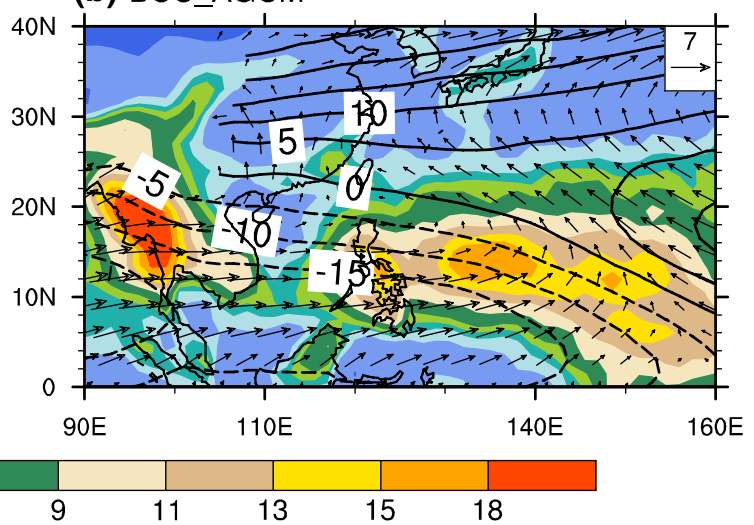

Fig. 1 May-September mean rainfall (shaded, $\mathrm{mm} \mathrm{day}^{-1}$ ), $850 \mathrm{hPa}$ winds (vector, $\mathrm{ms}^{-1}$ ) and vertical wind shear $\mathrm{U} 200-\mathrm{U} 850$ (contour with interval of $5 \mathrm{~ms}^{-1}$ ) from a observations (TRMM, ERAInterim) and b BCC_AGCM2.2 model simulations

\subsection{Observations and methodology}

The fundamental characteristics of the ISO are convective anomalies associated with heavy rainfall and/or outgoing long wave radiation (OLR). Therefore, daily rainfall estimates for 2002-2011 from the Tropical Rainfall Measuring Mission (TRMM, Huffman et al. 2007) 3B42 rainfall dataset with $0.25^{\circ} \times 0.25^{\circ}$ spatial resolutions and daily OLR data from the National Oceanic and Atmospheric Administration (NOAA, Liebmann and Smith 1996) are used for model evaluation of the simulated ISO. Reanalysis data from the interim European Centre for Medium-Range Weather Forecasts Re-Analysis (ERAInterim, Berrisford et al. 2009; Dee et al. 2011) is also used to aid the analysis of dynamic fields.

Vorticity is calculated using $\mathrm{u}$ and $\mathrm{v}$ wind components from ERAInterim. To focus on the intra-seasonal variability, the daily anomalies for both the observations and simulations are calculated by removing the annual cycle, composed of the time mean and the first three harmonics. Then, Lanczos band pass filters (Duchon 1979) with 200 weights and retaining periods of 20-70 days are applied to the anomaly data sets covering all the seasons. Finally, daily data corresponding to the boreal summer season (May-September) are extracted for analysis. Standard metrics, including estimation of variance, power spectra, lag correlation, and combined Empirical Orthogonal Function (CEOF) analysis, are applied to the filtered series. Apart from these metrics, by incorporating the methods outlined in Lin (2012), ISO-related variability is analyzed using composites of ISO events selected based on the two leading CEOF modes of the intra-seasonal OLR anomalies between $0^{\circ}$ and $42^{\circ} \mathrm{N}$.

Furthermore, the daily diabatic heating (apparent heating, $Q_{1}$ ) is calculated as the residual of a large-scale heat budget (Yanai et al. 1973):

$$
\mathrm{Q}_{1}=\mathrm{C}_{\mathrm{p}}\left(\frac{\mathrm{p}}{\mathrm{p}_{0}}\right)^{\frac{\mathrm{R}}{\mathrm{C}_{\mathrm{p}}}}\left(\frac{\partial \theta}{\partial t}+\vec{V} \cdot \nabla \theta+\omega \frac{\partial \theta}{\partial p}\right)
$$

where $C_{p}$ is the specific heat of air at constant pressure $\left(* 1004 \mathrm{~J} \mathrm{~kg}^{-1} \mathrm{~K}^{-1}\right), \mathrm{R}$ is the gas constant for dry air $\left(* 287 \mathrm{~J} \mathrm{~kg}^{-1} \mathrm{~K}^{-1}\right), \mathrm{p}_{0}$ is the reference pressure $\left(* 10^{5} \mathrm{~Pa}\right)$ and $\theta$ is the potential temperature of the air parcel.

\section{Results}

\subsection{Mean states}

In this section, we will first describe some aspects of the seasonal mean climatology that may impact on intra-seasonal variability during boreal summer. Figure 1 shows the observed and simulated May-September mean rainfall, 850-hPa wind field, and vertical shear in zonal wind over the EA-WNP region. In observations, a cyclonic low-level circulation associated with the monsoon trough prevails over the South China Sea, and an extended anticyclonic circulation, which is part of the WNP Subtropical High (WNPSH), dominates the WNP region. These flow-patterns are accompanied by an elongated rain belt extending from the eastern South China Sea to southern Japan, with a heavy precipitation centered over the Philippine Sea (Fig. 1a). Figure $1 \mathrm{~b}$ shows the BCC_AGCM2.2 simulations. The spatial pattern correlation coefficient of precipitation between the observation and the simulation is 0.83 , while the rootmean-square error is $2.89 \mathrm{~mm} \mathrm{day}^{-1}$. However, the model slightly underestimates the mean rainfall over the EA summer monsoon region (EASM) and overestimates the rainfall over the most of WNP. Similar model biases can also be seen from $850 \mathrm{hPa}$ winds. For example, the position of a 

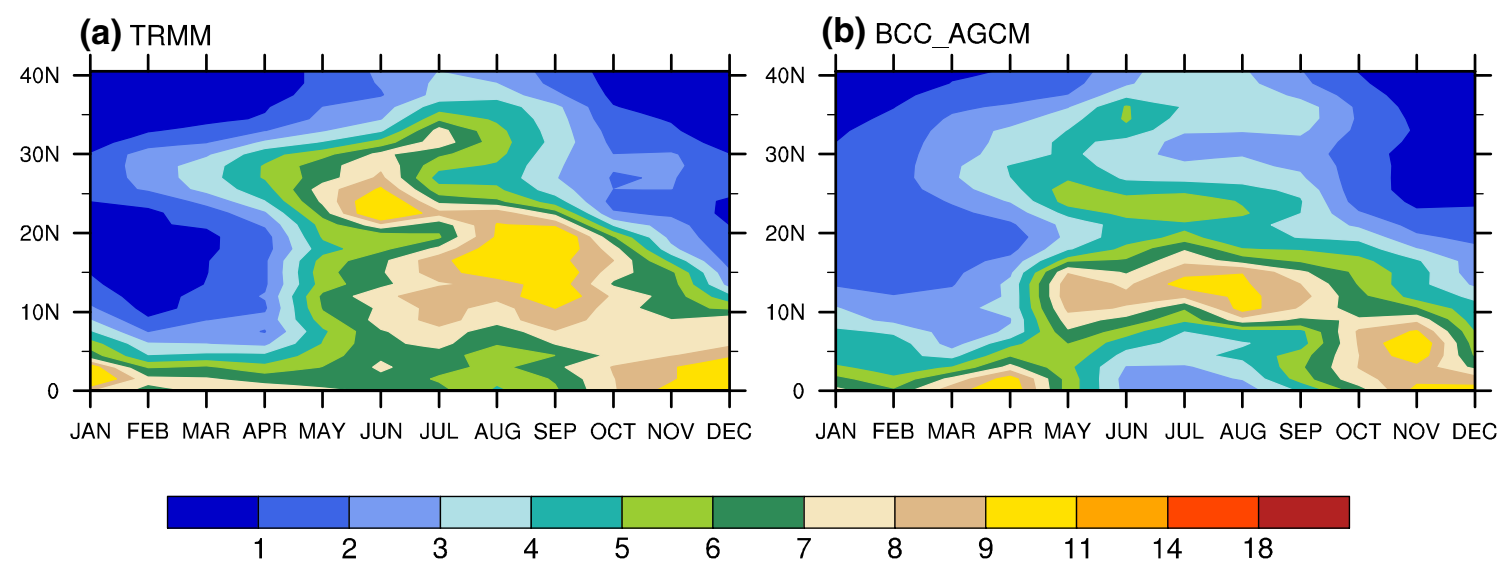

Fig. 2 Time-latitude cross section of precipitation $\left(\mathrm{mm} \mathrm{day}^{-1}\right)$ averaged over $105-120^{\circ}$ E from a TRMM and $\mathbf{b}$ BCC_AGCM2.2 model simulations

WNP anticyclonic circulation in the model is shifted to the east compared to ERAInterim, consistent with the dry bias in the EASM region. Westerly winds along the $10-20^{\circ} \mathrm{N}$ band are much stronger in the model than in ERAInterim, driving the wet bias in WNP region.

Vertical shear in zonal winds between 200 and $850 \mathrm{hPa}$ is known to be a key factor for the summer ISO activity over the EA-WNP region (Wang and Xie 1997; Sperber and Annamalai 2008). It acts to regulate ISO activity through the modulation of Rossby wave emissions from ISO associated diabatic heating over the equatorial Pacific Ocean (Zhang and Geller 1994; Chou and Hsueh 2010; Mao et al. 2010). The model captures the observed overall pattern with easterly shear over the equatorial Pacific south of $20^{\circ} \mathrm{N}$, but the shear is slightly stronger than observations.

In order to examine whether the model correctly simulates the onset and withdrawal of the EA-WNP summer monsoon, the annual cycle of the precipitation averaged over $105-122^{\circ} \mathrm{E}$ is shown in Fig. 2. It is found that the BCC_AGCM2.2 can reasonably simulate the phase of the annual cycle with stepwise northward propagation of the monsoon rain band from $15^{\circ}$ to $40^{\circ} \mathrm{N}$ (Fig. 2b). However, the modeled onset of the South China Sea monsoon rainfall begins at early May, earlier about 1 month than the observation. The strength of the rain belt from May to September is underestimated over both the South China Sea and eastern China region, which is consistent with bias in the seasonal mean rainfall as shown in Fig. 1 b.

\subsection{Power spectrum and variance}

Figure 3 shows comparisons of 10 year averages of modeled power spectra in OLR (Fig. 3b, d) with observations (Fig. 3a, c) for the WNP $\left(110-155^{\circ} \mathrm{E}, 0-20^{\circ} \mathrm{N}\right)$ and the EASM region $\left(100-140^{\circ} \mathrm{E}, 20-40^{\circ} \mathrm{N}\right)$. Spectral analysis is applied to the daily time series of OLR during May to October each year and then averaged over the 10 year period of 2002-2011. In observation, it is found that two frequency bands equivalent to the 20-70- and 10-20-day periods dominate the BSISO over the EA-WNP region. This is consistent with many previous studies (e.g., Hsu and Weng 2001; Lin 2012), which concluded that the shorter variations of 10-20 days propagate mainly westward between $5^{\circ}$ and $15^{\circ} \mathrm{N}$, and when doing a zonal average, only the northward propagating variations of 20-70 days remain. The simulation shows the spectral power to be statistically significant near the period of 30 days and between 10 and 20 days, similar to that from observation (Fig. 3b, d). However, the observed 45 and 20 day peaks over the WNP region are absent in the model (Fig. 3b). The simulated 20 day peak over the EASM is not in agreement with the observation (Fig. 3d). Note also that the variance of simulated power spectrum peaks is underestimated (overestimated) over WNP (EASM) region (Fig. 3b, d). Overall, the model captures the dominant frequencies of BSISO on intra-seasonal time scales over the EA-WNP region.

Figure 4 compares the geographic distributions of observed and modeled ISO intensity over the EA-WNP region using the standard deviation of the 20-70 day band-pass filtered rainfall anomalies during May-September. The patterns look largely similar, but the model simulation has clearly exaggerated the amplitudes. In observations, the ISO component of precipitation perturbation shows a similar structure to its mean state (Fig. 1a), with maxima located over the north of the South China Sea, the Philippine Sea, and East China Sea (see Fig. 4a). The model underestimates ISO intensity over the EASM region, while it is overestimates over part of the WNP region, especially to the east of $140^{\circ} \mathrm{E}$ (Fig. $4 \mathrm{~b}$ ). The similarity between Figs. $1 \mathrm{~b}$ and $4 \mathrm{~b}$ suggests that biases in simulated BSISO intensity are related to the 


\section{(a) $\operatorname{NOAA}(\mathrm{OLR})$}

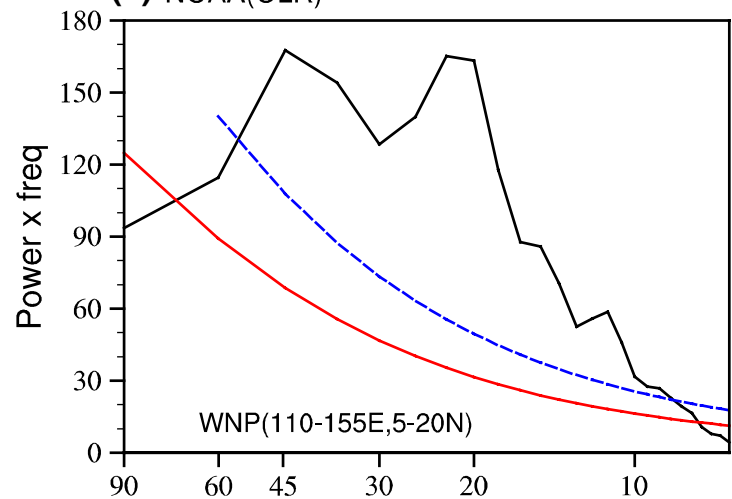

(c) NOAA(OLR)

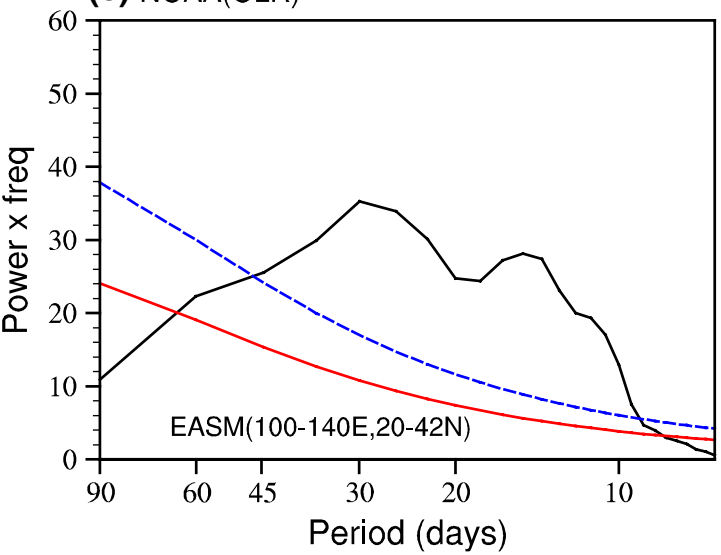

Fig. 3 Comparison of mean OLR power spectrums for the period 2002-2011 for the western North Pacific (a, b) and East Asia Summer Monsoon region $(\mathbf{c}, \mathbf{d})$ between observations (NOAA reanalysis) (b) BCC AGCM

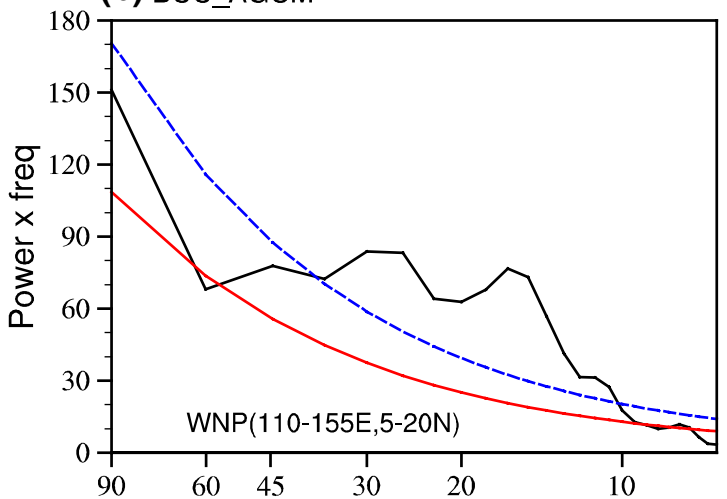

(d) BCC_AGCM

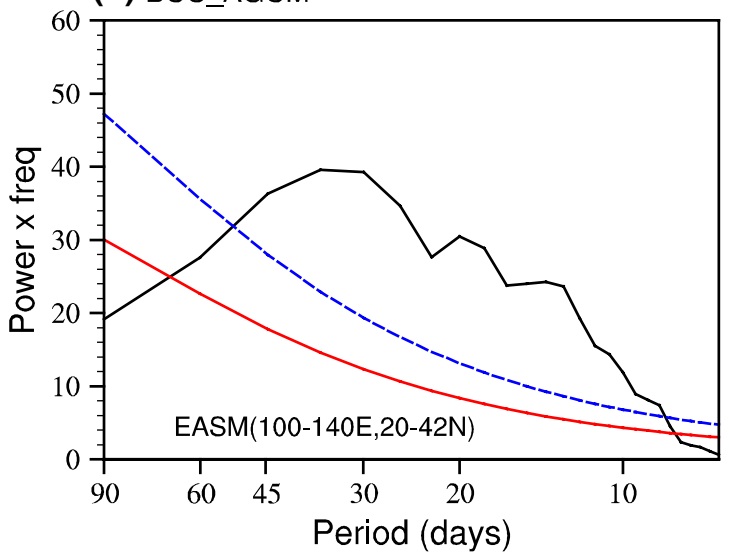

and model simulations, where red line shows the Markov red noise spectrum and the dashed blue $95 \%$ confidence level (a) TRMM

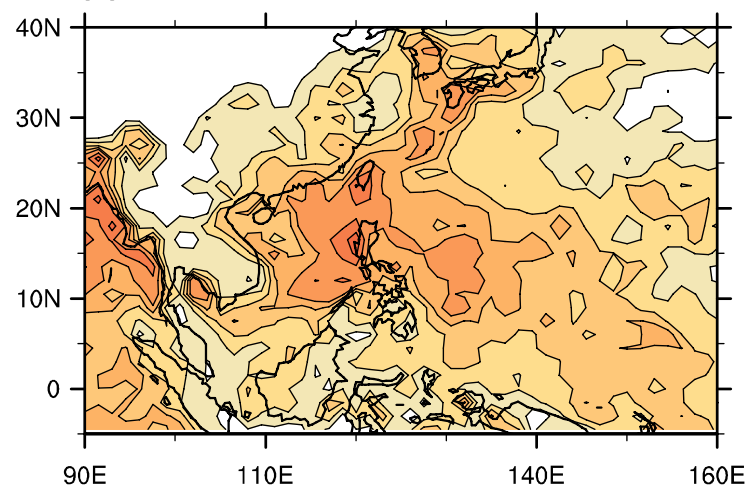

(b) BCC_AGCM

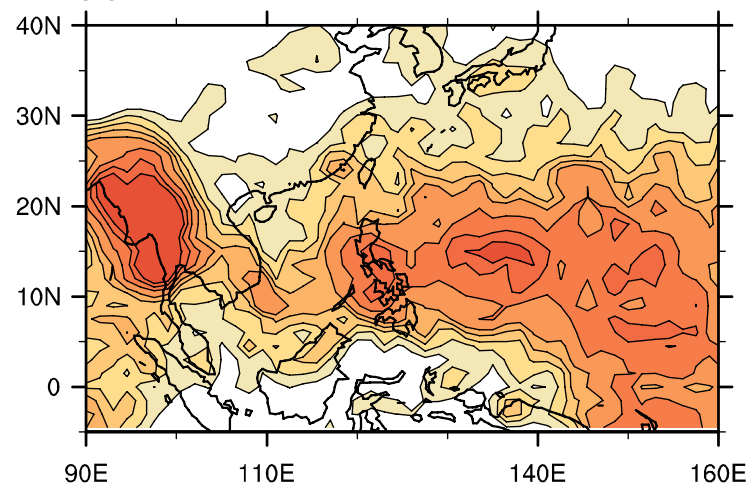

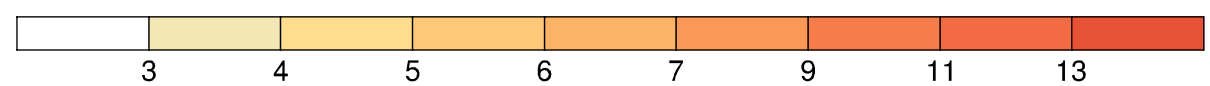

Fig. 4 Comparison of May-September standard deviations of intra-seasonal precipitation rate $\left(\mathrm{mm} \mathrm{day}^{-1}\right)$ between TRMM observations (a) and BCC_AGCM2.2 model simulations (b) 
(a) NOAA(ERAI) EOF1

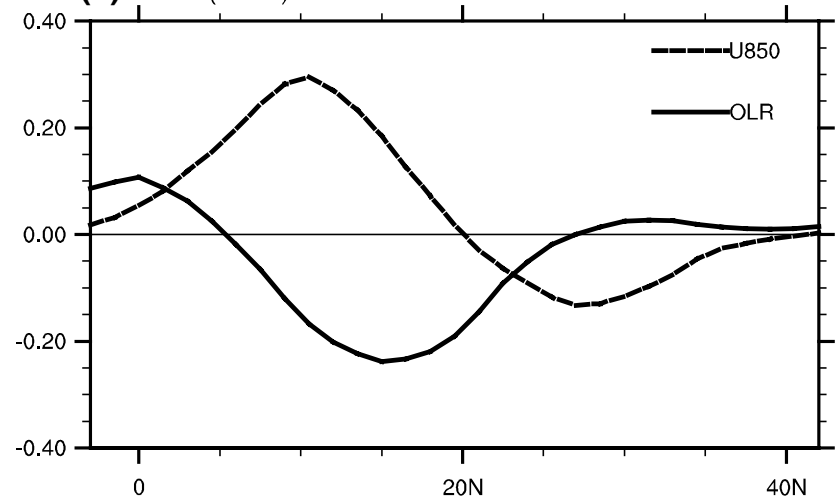

(c) BCC_AGCM EOF1

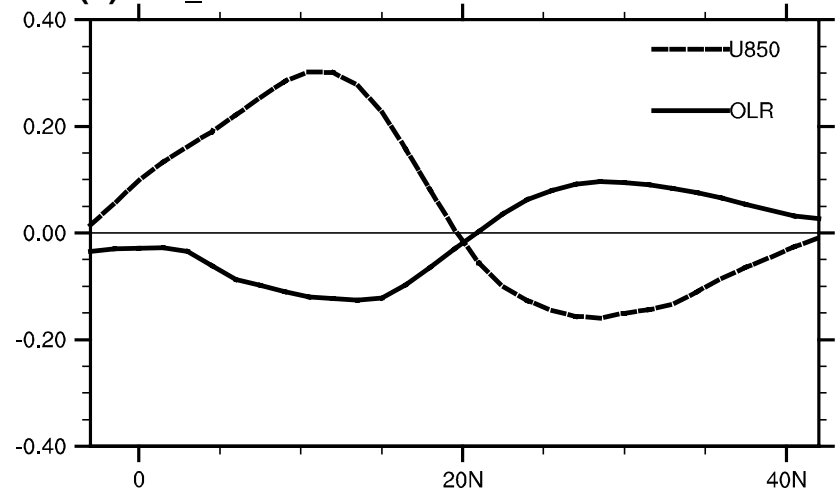

Fig. 5 Comparison of spatial structures of the first two combined EOF modes between observations (top) and model simulations (bottom) for the period 2002-2011, where solid lines are intra-seasonal

erroneous simulation of the seasonal mean precipitation, as reported by previous studies (Sperber and Annamalai 2008; Sabeerali et al. 2013).

\subsection{Combined EOF analysis}

EOF analysis has been widely used to separate the phase structures of the tropical intra-seasonal variability from the filtered time series (Shukla 2014). A recent study by Lin (2012) applied the combined EOF analysis to fields of daily anomalies of intra-seasonal OLR and $850 \mathrm{hPa}$ zonal winds (U850) averaged over $90-150^{\circ} \mathrm{E}$. It was found that the first two EOF modes combined with their principal components can reasonably well represent the northward propagation of the BSISO over the EA-WNP region.

Figure 5 shows the latitudinal distribution of the two leading EOFs of the intra-seasonal OLR and U850 averaged over $100-150^{\circ} \mathrm{E}$ from observations (top) and model simulations (bottom). In observations, the first two leading modes jointly explain more than $60 \%$ of the total variance. EOF1 is characterized by enhanced convection centered near $15^{\circ} \mathrm{N}$ with easterly anomalies to the north and westerly (b) NOAA(ERAI) EOF2

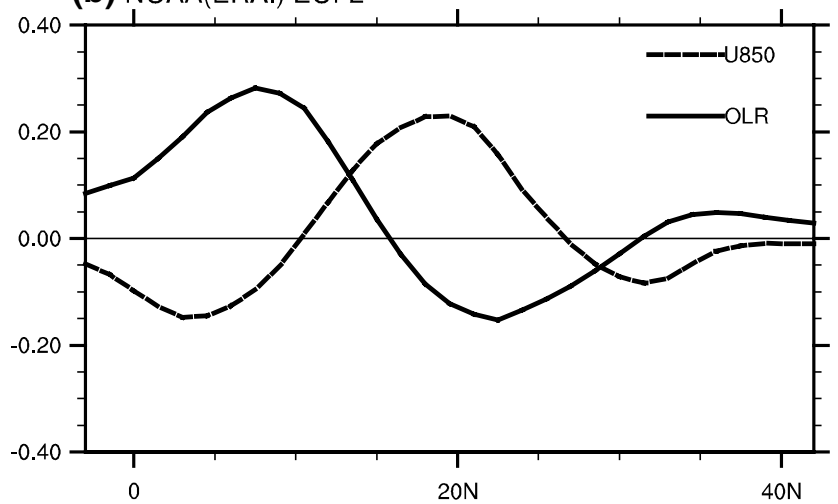

(d) BCC_AGCM EOF2

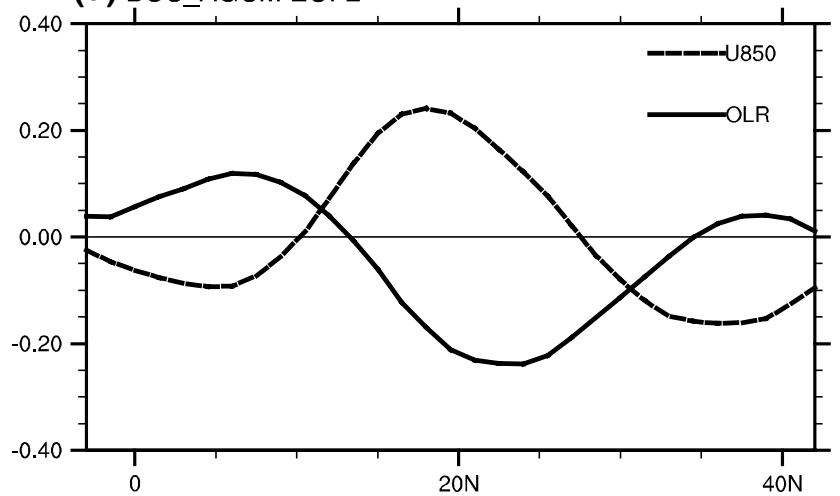

OLR and dashed lines are $850 \mathrm{hPa}$ zonal winds (U850) averaged between 100 and $150^{\circ} \mathrm{E}$. OLR data are from NOAA and U850 from ERAInterim

anomalies to the south, whereas for EOF2, both convection and wind patterns are in close quadrature with EOF1. Taken as a pair, these structures are consistent with those obtained by the previous study of Lin (2012). The corresponding principal components (PCs) are also in quadrature with PC1 leading PC2 by 9 days (lagged correlation of 0.67; figure not shown). The first two EOFs from model simulations (shown in Fig. 5c, d) jointly account for $40 \%$ of the total variance with similar meridional structures and phase relationships to observations (Fig. 5a, b). The phase shift between PC1 and PC2 in the model is 11 days compared to 9 days in observations.

\subsection{Horizontal and vertical structures}

Figure 6 shows the composited life cycle of the 20-70 day filtered precipitation anomalies and $850 \mathrm{hPa}$ wind fields following Lin (2012). The life cycle of an ISO event is defined in a phase space using the combined first two EOFs by plotting PC2 against PC1. The PC1-PC2 plane is divided into eight portions representing the eight phases. Daily fields falling into each portion are used for the phase 

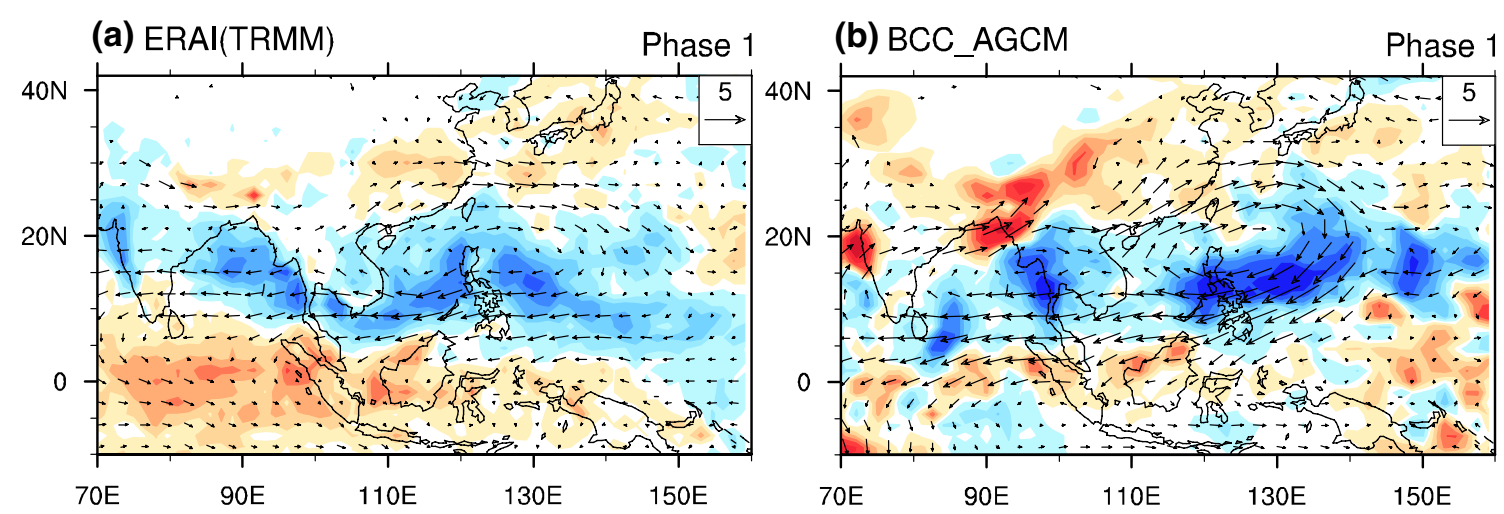

(c) ERAI(TRMM)

Phase 3

(d) BCC_AGCM

Phase 3
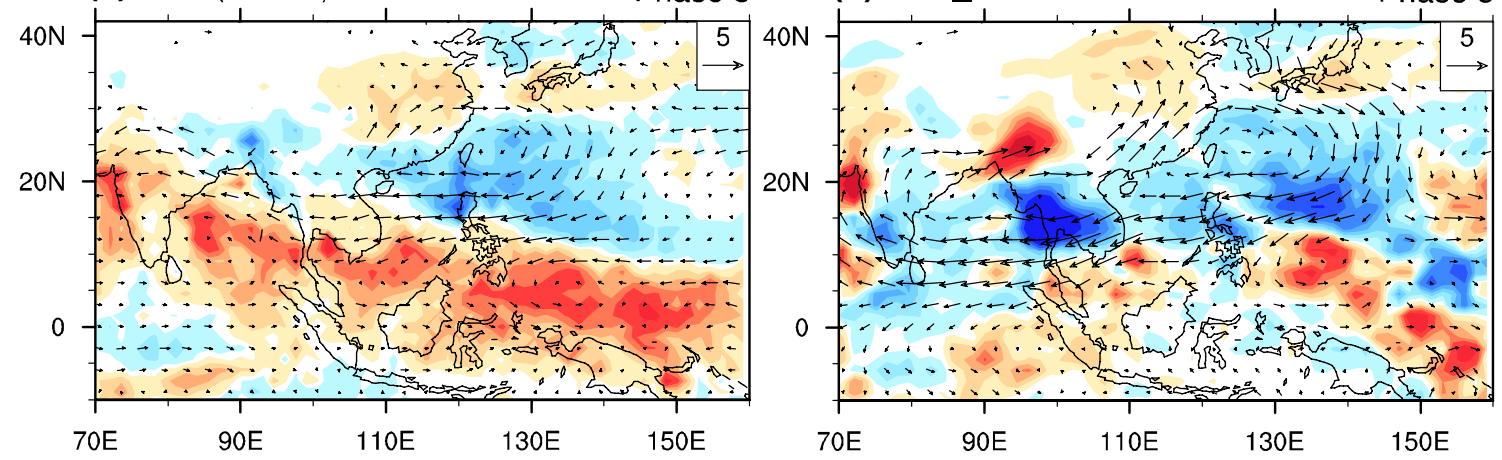

(e) ERAI(TRMM)

Phase 5 (f) BCC_AGCM
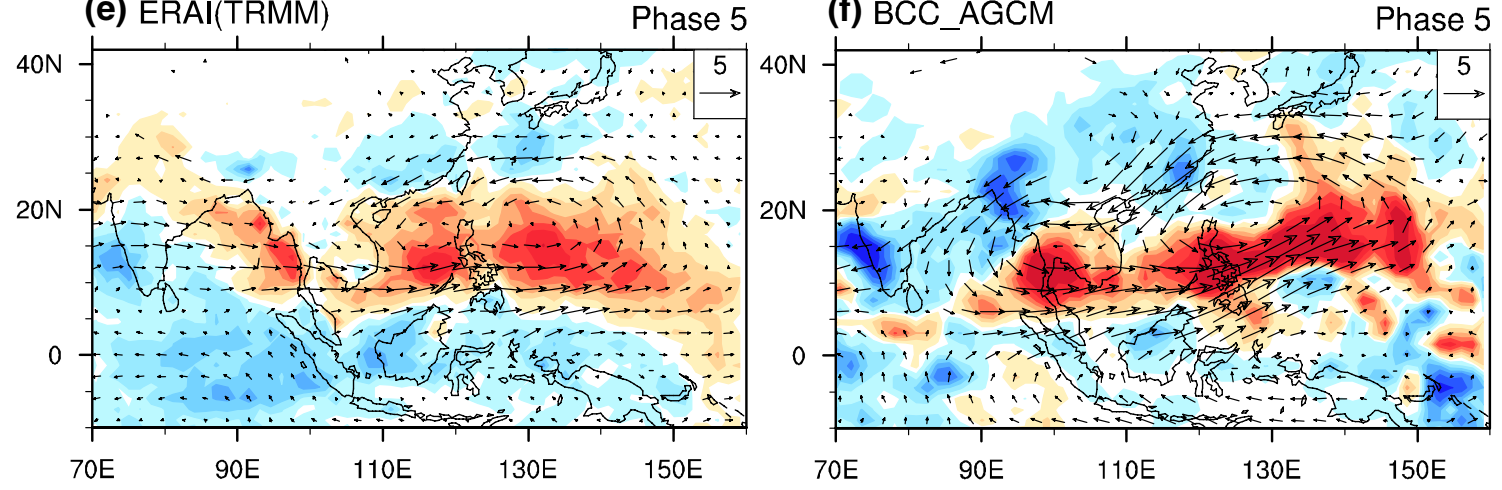

(g) ERAI(TRMM)

Phase 7

(h) BCC_AGCM

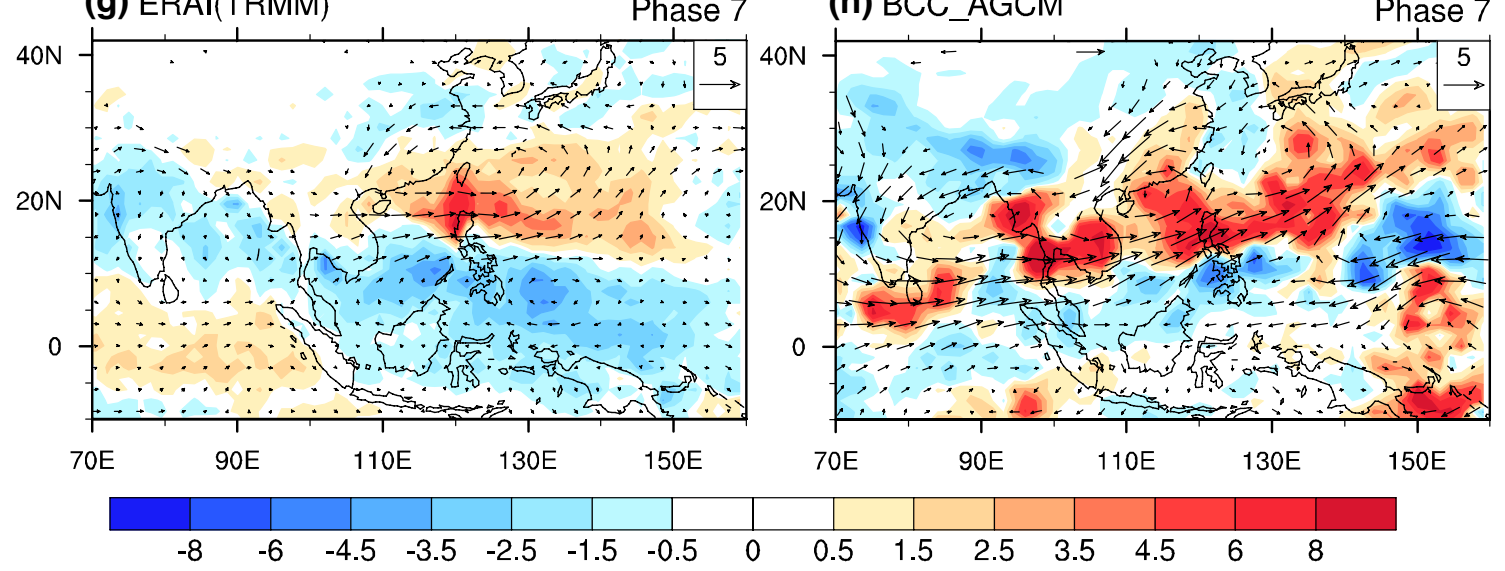

Fig. 6 Composites of precipitation (color, $\mathrm{mm} \mathrm{day}^{-1}$ ) and $850 \mathrm{hPa}$ wind anomalies (vectors, $\mathrm{m} \mathrm{s}^{-1}$ ) for phase 1, 3, 5 and 7 from observations (left, ERAInterim and TRMM) and BCC_AGCM2.2 model simulations (right) 
Table 1 Number of days for each phase of the BSISO

\begin{tabular}{|c|c|c|c|c|c|c|c|c|}
\hline & \multicolumn{8}{|c|}{ Phase } \\
\hline & 1 & 2 & 3 & 4 & 5 & 6 & 7 & 8 \\
\hline Observation & 137 & 97 & 116 & 171 & 125 & 116 & 143 & 141 \\
\hline BCC_AGCM & 103 & 59 & 108 & 199 & 92 & 65 & 88 & 184 \\
\hline
\end{tabular}

composite if the amplitudes $\left(P C 1^{2}+P C 2^{2}\right)$ exceed 1 (the strong ISO area that lies outside the one unit circle on the phase-space diagram, see Fig. 7 in Lin 2012). It is found that BCC_AGCM2.2 overestimates the number of days for phase 4 and 8 , while underestimates them for other phases (Table 1). Phase 1, 3, 5 and 7 from observations are shown in the left column in Fig. 6 to compare with model simulations on the right. The entire evolution of the observed ISO cycle shows a pattern with a well-organized anomalous cyclone (anticyclone) in conjunction with the peak enhanced (suppressed) convection alternately dominating the South China Sea and WNP, forming a seesaw circulation-convection pattern between the EA and WNP region. Such a flow structure, consistent with that reported by Mao et al. (2010) and Lin (2012), is similar to the analytical solution for a symmetric heating source about the equator (Gill 1980), indicating a Rossby wave-like behavior of the coupled circulation-convection system. Note that the northward propagation of the BSISO is accompanied with eastward movement of the northwest-southeast tilted convection front across the Maritime Continent. This indicates that the EA-WNP BSISO partly originates in the Indian Ocean, which is consistent with many previous studies (Wang and Xie 1997; Jiang and Li 2005).

The BCC_AGCM2.2 captures most of the observed features of $850-\mathrm{hPa}$ wind and convective anomalies for the composited BSISO cycle, especially for the alternating development of the cyclone and anticyclone anomaly anchored over the South China Sea and Philippine Sea. However, there exist systematic discrepancies in the location and magnitude of the anomaly centers. For example, the anomalous cyclone and anticyclone for all the phases is stronger and extends more westward, followed by a stronger amplitude and broader range in the simulated precipitation anomalies than that in the observation (Fig. 6b, $\mathrm{d}, \mathrm{f}, \mathrm{h}$ ). Moreover, the model cannot simulate the eastward propagating convection across the Maritime Continent, and the modeled pattern shows a southwest to northeast tilt of the precipitation and circulation anomaly. These biases may be associated with a strong and westward extension of WNPSH simulated in BCC_AGCM2.2, which will be detailed explored later.

Figure 7 compares the vertical dynamic and thermodynamic structures following Jiang et al. (2011) and Abhik et al. (2013). This includes anomalous vorticity, specific humidity, equivalent potential temperature, cloud liquid water, vertical velocity and diabatic heating with observations on top and model simulations at the bottom. The meridional-vertical structure is composited with respect to the maximum convection center (MCC) at various latitudes within $10-30^{\circ} \mathrm{N}$ during phase $6-8$, when the ISO-related rain bands propagate northward from the WNP to the EA region. The positive (negative) numbers in the abscissa correspond to the distance in degrees to the north (south) direction with respect to the MCC.

It is clear that the BCC_AGCM2.2 model captures the gross features of vertical structures of northward propagating BSISOs. The vertical distribution of vorticity shows (Fig. 7a, f) an equivalent barotropic structure and the centers of positive vorticity lay about $1-2^{\circ} \mathrm{N}$ of MCC. Maximum specific humidity occurs in the lower troposphere to the north of the MCC (Fig. 7b, g), contributing to the enhancement of the convective instability by higher equivalent potential temperature (Fig. 7c, h). The abundance of moisture to the north of the MCC leads to the formation of cloud liquid water (Fig. 7d, i), which tilts southward with height and eventually manifests in the vertical heating profile with maximum presented in the middle troposphere (Fig. 7e, j). The asymmetric structure relative to the $\mathrm{MCC}$ is found to be a key feature for the northward propagation of the BSISO (Jiang et al. 2004). Note that the modeled maxima of specific humidity, equivalent potential temperature and cloud liquid water to the north of MCC are stronger but positioned lower than observations. This implies that deep convection can start from the boundary layer with enhanced vertical moisture transport (Fig. 7d, i), resulting in unrealistic strong heating (Fig. 7e, j), which further strength the northward displacement of the ISO convection by enhancing the instability and low level moisture convergence as shown in the next Section.

\subsection{Northward propagation}

Another important characteristic of the BSISO is the northward propagation. Figure 8 shows the lag-correlation coefficients between area-averaged precipitation over the South China Sea and Philippine Sea $\left(10^{\circ}-20^{\circ} \mathrm{N}, 110^{\circ}-135^{\circ} \mathrm{E}\right)$, where the BSISO has a maximum variance (Fig. 4a, b), and $120^{\circ}-135^{\circ} \mathrm{E}$ zonal mean precipitation (color shaded) and U850 (contours). Figure $8 \mathrm{~b}$ (model) compares favorably with Fig. 8a (observations) in overall northward 

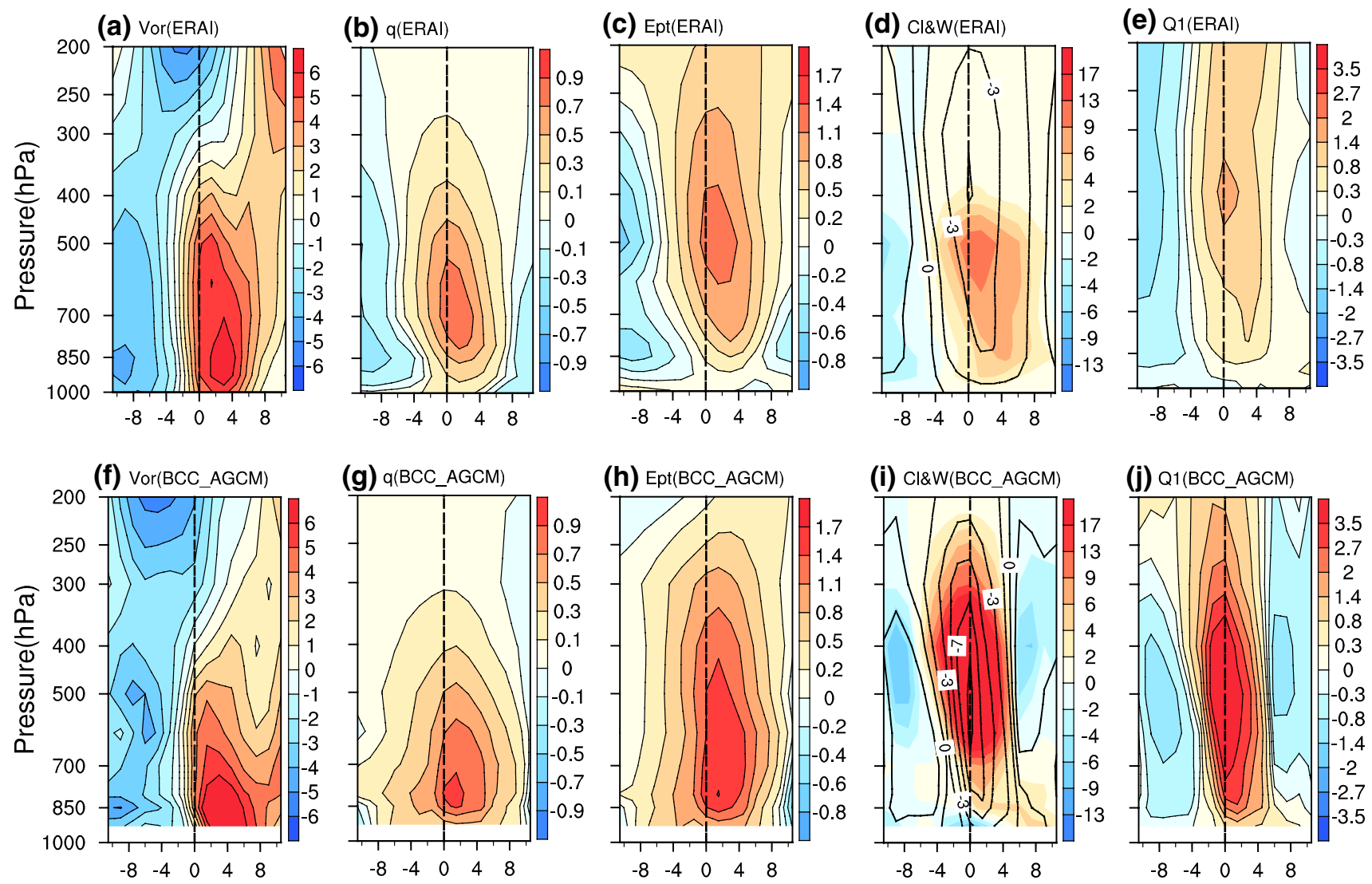

Fig. 7 Composite dynamical and thermodynamical vertical structures of northward propagating BSISO events centred around maximum convections for ERAinterim (top) and model simulations (bottom): a, $\mathbf{f}$ are vorticity $\left(10^{-6} \mathrm{~s}^{-1}\right) ; \mathbf{b}, \mathbf{g}$ specific humidity $\left(\mathrm{g} \mathrm{kg}^{-1}\right)$; c, $\mathbf{h}$ equivalent potential temperature $(\mathrm{K}) ; \mathbf{d}, \mathbf{i}$ cloud liquid water (shaded, $\mathrm{mg} \mathrm{m}^{-1}$ ) and vertical velocity contours with an interval of $10^{-2} \mathrm{~Pa} \mathrm{~s}^{-1}$; e, j diabatic heating $\left(\mathrm{K} \mathrm{day}^{-1}\right)$. Horizontal axis shows the meridional distance (degree) with respect to maximum convection center with positive to the north (a) TRMM(ERAI)

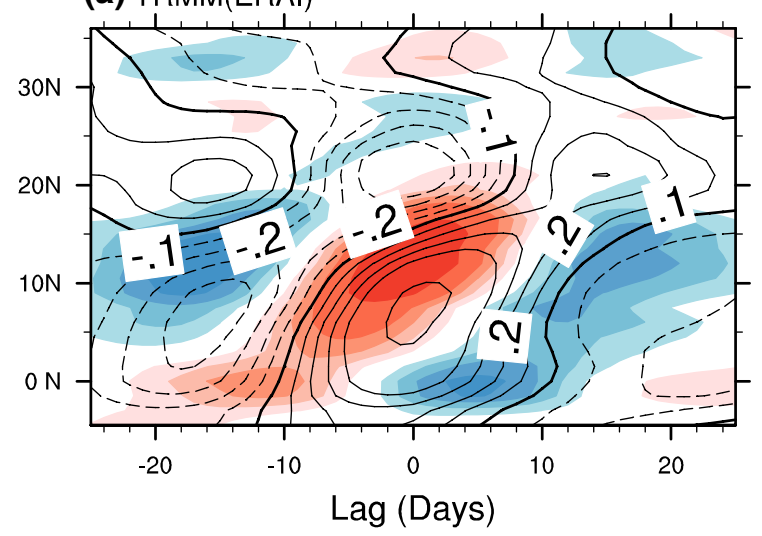

(b) BCC_AGCM

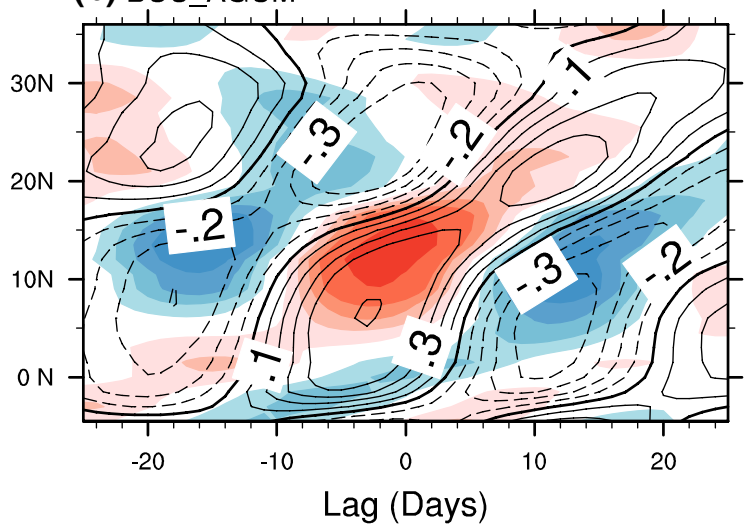

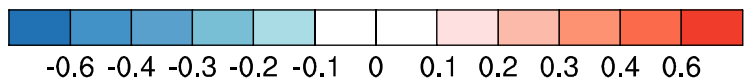

Fig. 8 Lag correlation between regional average precipitation anomalies over the South China Sea and Philippine Sea $\left(110-135^{\circ} \mathrm{E}, 10^{-}\right.$ $20^{\circ} \mathrm{N}$ ) and zonal mean precipitation anomalies (shaded) and U850 for $120-135^{\circ} \mathrm{E}$. All fields are 20-70 day band-pass filtered for May-September during 2002-2011: a TRMM and ERAInterim and b BCC_ AGCM2.2 
propagation features, but there are regional differences in magnitude and phase speed. The modeled BSISO signals also propagate further north than observations suggest.

Given the importance of moist processes in BSISO propagation, the moisture-convection feedback mechanism of Jiang et al. (2004) is further examined in model simulations, which explains how meridional asymmetry of moisture distribution leads to the northward shift of convection. It is hypothesized that boundary layer moisture advection is, at least partially, responsible for the asymmetry of the specific humidity with respect to the MCC:

$\frac{\partial \mathrm{q}^{\prime}}{\partial \mathrm{t}} \propto-\overline{\mathrm{v}} \frac{\partial \mathrm{q}^{\prime}}{\partial \mathrm{y}}-\mathrm{v}^{\prime} \frac{\partial \overline{\mathrm{q}}}{\partial \mathrm{y}}-$ omega $^{\prime} \frac{\partial \overline{\mathrm{q}}}{\partial \mathrm{p}}-\overline{\text { omega }} \frac{\partial \mathrm{q}^{\prime}}{\partial \mathrm{p}}-\left(\frac{\mathrm{Q}_{2}}{\mathrm{~L}}\right)^{\prime}$

where $\mathrm{v}$ is the meridional flow, $\mathrm{q}$ is the moisture field; omega represents the vertical motion induced by the BSISO convection in boundary layer, and $\frac{\mathrm{Q}_{2}}{\mathrm{~L}}$ denotes the moisture source or sink (primarily determined by surface evaporation and atmospheric condensation). The overbar, “-”, represents the seasonal mean and the prime, ",", denotes the boreal summer intra-seasonal perturbation. Correlation coefficients similar to Fig. 8 for the above six terms averaged in the lower troposphere $(1000-700 \mathrm{hPa})$ are shown in Fig. 9, where the left are observations and the right are model simulations. It is clear from both observations and model simulations (see Fig. 9a, b) that positive $\mathrm{q}^{\prime}$ tendencies in (color shaded) lead precipitation anomalies (contours) and convection (Fig. 9g, h). To the first order, the meridional asymmetry of the $\mathrm{q}^{\prime}$ tendency is determined by the meridional advection terms (Fig. 9c-f), which show large positive contributions to the north of MCC. The $\overline{\text { omega }} \frac{\partial \mathrm{q}^{\prime}}{\partial \mathrm{p}}$ term has a positive contribution (Fig. 9i, j), while omega' $\frac{\partial \bar{q}}{\partial p}$ term plays a negative contribution (Fig. 9g, h). The $\left(\frac{\mathrm{Q}_{2}}{\mathrm{~L}}\right)^{\prime}$ term is approximately out of phase with the precipitation anomalies, thus also play an important role in causing the boundary layer moisture asymmetry (Fig. 9k, l). It is found that modeled $\mathrm{q}^{\prime}$ tendency signal is stronger and propagates further north (reaches $\left.30^{\circ} \mathrm{N}\right)$ than observations show $\left(\sim 20^{\circ} \mathrm{N}\right)$, which is consistent with the northward shift of modeled convection signals. This bias is seemed to be resulted from the unrealistically strong northward-propagating signal of $\mathrm{v}^{\prime} \frac{\partial \overline{\mathrm{q}}}{\partial \mathrm{y}}, \overline{\text { omega }} \frac{\partial \mathrm{q}^{\prime}}{\partial \mathrm{p}}$, and especially the $\left(\frac{\mathrm{Q}_{2}}{\mathrm{~L}}\right)^{\prime}$ term in the model (Fig. 9d, j, l). The bias of $\left(\frac{Q_{2}}{L}\right)^{\prime}$ signal indicates that the region to the north of MCC in the model is a stronger apparent moisture source with evaporation exceeding precipitation, which is probably due to the strong and northward shift of simulated WNP subtropical high (see Sect. 3.6).

\subsection{Intra-seasonal variability of the Western North Pacific Subtropical High}

It is well known that the seasonal and sub-seasonal migration of the rain-band over EA-WNP is strongly influenced by the WNPSH through the modulation of moisture transport (Ding and Chan 2005; Mao et al. 2010; Ren et al. 2013). We have seen in Sect. 3.4 that the northward propagating BSISOs manifest by the alternation between cyclonic and anticyclonic circulation anomalies accompanied by enhanced (suppressed) convection over WNP region. This is, in fact, a reflection of the intra-seasonal variability of the WNPSH.

Figure 10 contrasts the composite unfiltered (contour) and filtered (shaded) $500 \mathrm{hPa}$ geopotential height for phase 1 and 5, the wettest and the driest two phases of the ISO for the WNP rainfall, between observations (left) and model simulations (right). The observed ISOs are characterized by a north-south dipole structure in anomalous geopotential height, corresponding to the westward extension and eastward retreat of the WNPSH (Fig. 10a, c). The model qualitatively mimics the observed variability of the WNPSH, but the ridge is positioned far too north and the westward extension enters much further over land (Fig. 10b, d). The positional bias allows the BSISO anomalies to propagate further north compared to observations.

Next we carry out further analysis to understand the bias in simulated WNPSH. It is believed that diabatic heating associated with the Asian summer monsoon rainfall affects the summer subtropical circulation over the North Pacific (Rodwell and Hoskins 2001; Zhou et al. 2009). Figure 11 shows the model bias in vertical integrated diabatic heating (shaded) from the surface to 200 and $850 \mathrm{hPa}$ non-divergent flow (vector) for phase 1 and 5. A common feature seen in both phases is the positive heating bias over the WNP region in connection with seasonal mean precipitation errors shown in Fig. $2 b$ and cloud liquid water biases shown in Fig. 7 h. Associated with the wet anomalies induced positive heating biases is a strong cyclonic on the northwest flank of the heating with strong westerly anomaly concentrated between the $0-15^{\circ} \mathrm{N}$ over the tropical western Pacific Ocean. Strong easterly anomaly can be found on the east side of the heating. Such a flow pattern is similar to the analytical solution for a combination of antisymmetric and symmetric heating source (Gill 1980). It seems reasonable to suggest that it is the wet bias associated with diabatic heating that drives the northwestward extension of WNPSH allowing further northward propagation of the BSISOs. Moreover, similar to the classical Gill solution (Gill 1980), the circulation 
Fig. 9 Same as Fig. 8 where contours are precipitation anomalies with interval of 0.2 but shades are for $\mathbf{a}, \mathbf{b} \frac{\partial \mathbf{q}^{\prime}}{\partial \mathrm{t}} ; \mathbf{c}$, $\mathbf{d}-\mathrm{v}^{\prime} \cdot \frac{\partial \overline{\mathrm{q}}}{\partial \mathrm{y}} ; \mathbf{e}, \mathbf{f}-\overline{\mathrm{v}} \cdot \frac{\partial \mathrm{q}^{\prime}}{\partial \mathrm{y}} ; \mathbf{g}, \mathbf{h}$ -omega' $\frac{\partial \overline{\mathrm{q}}}{\partial \mathrm{p}} ; \mathbf{i}, \mathbf{j}$-omega $\frac{\partial \mathrm{q}^{\prime}}{\partial \mathrm{p}}$; and (k), (1) $\left(\frac{\mathrm{Q}_{2}}{\mathrm{~L}}\right)^{\prime}$. Left side shows observations and right model simulations

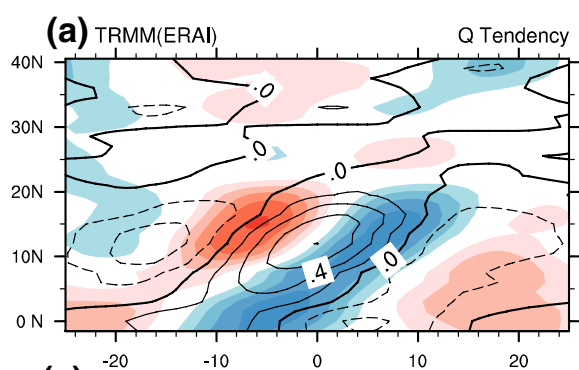

(b) BCC_AGCM

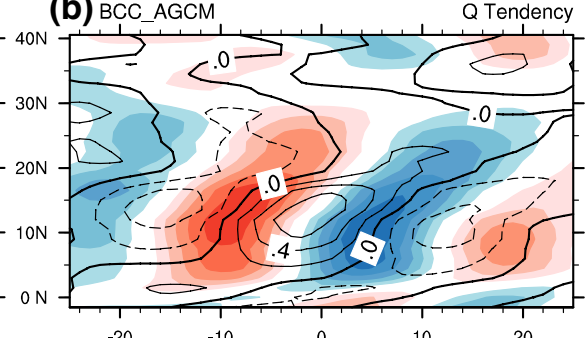

(c) TRMM(ERAI) ${ }^{-20}$ Vano.Qclm Gradient $^{-10}$

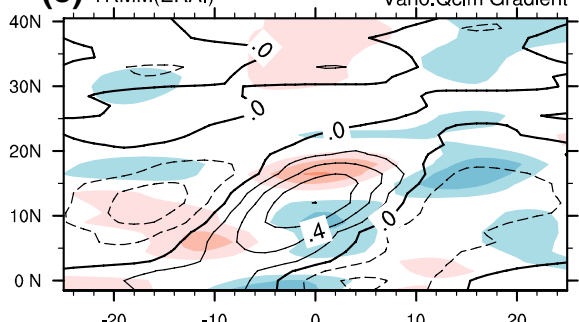

(e) ${ }^{-20}$ TRMM(ERAI)

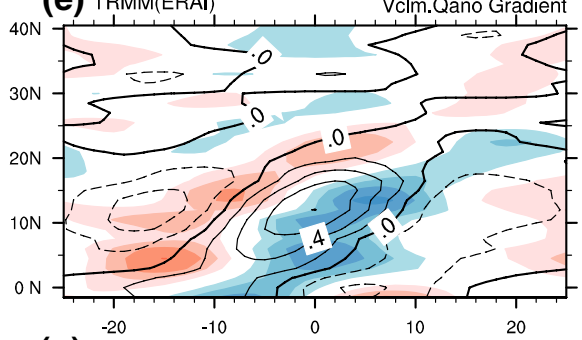

(g) TRMM(ERAI)
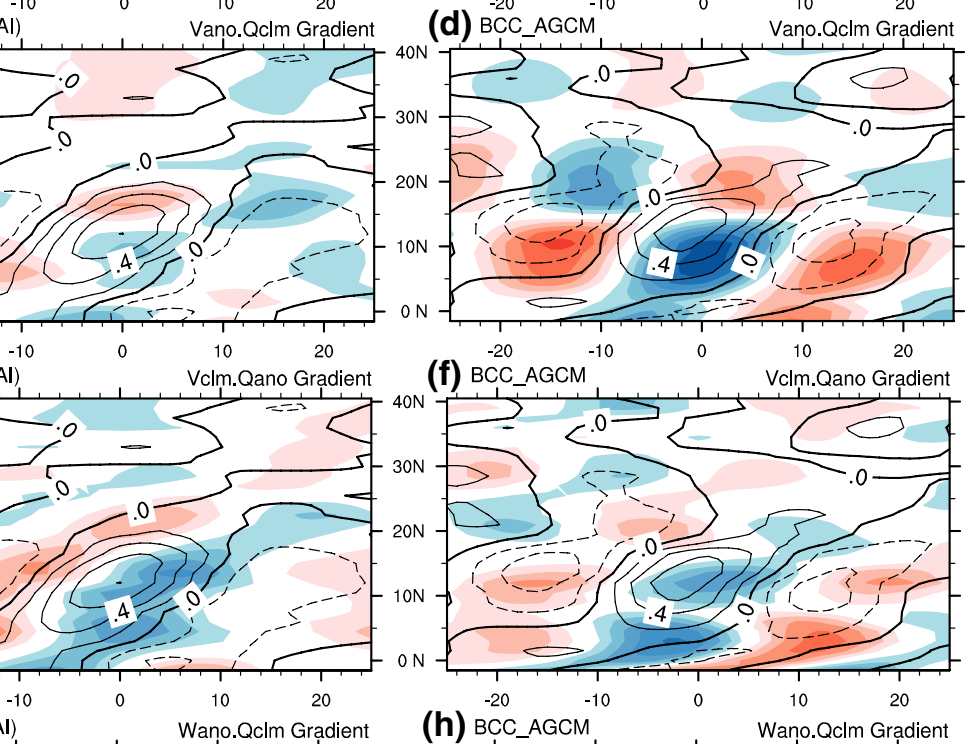

(h) ${ }^{-20}{ }^{-1}{ }_{1}{ }^{-10}$ AGCM
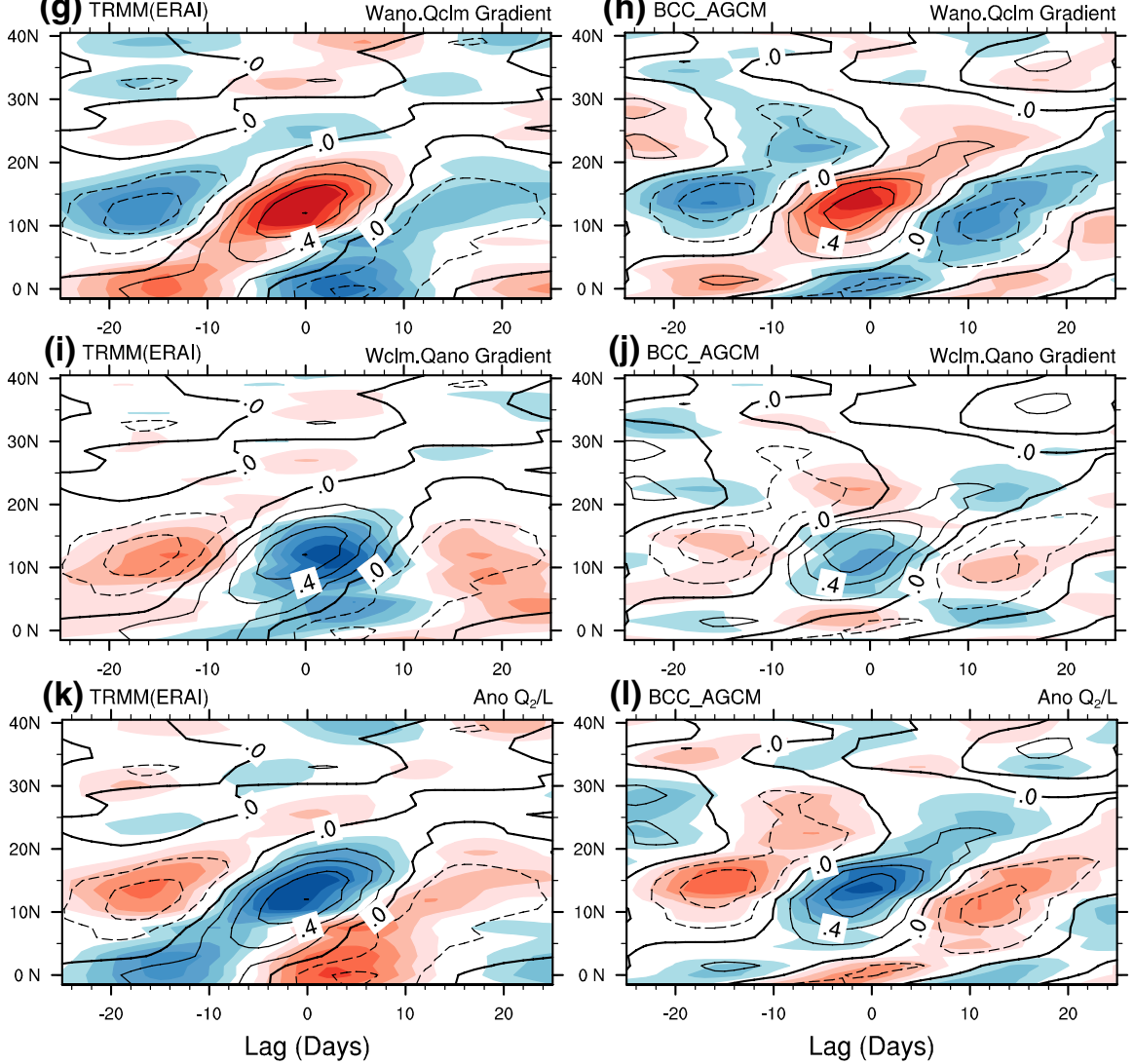

(I) BCC_AGCM
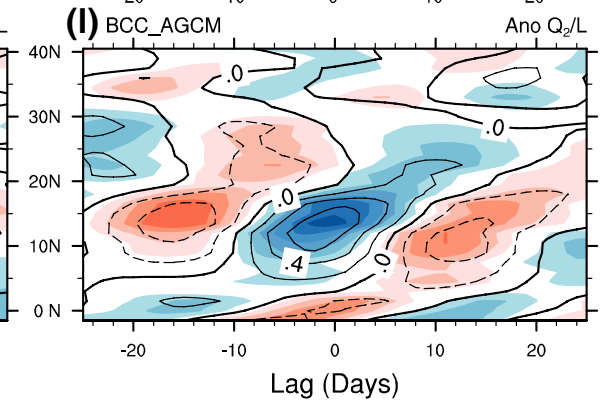

$\begin{array}{lllllllllllll}-0.6 & -0.5 & -0.4 & -0.3 & -0.2 & -0.1 & 0 & 0.1 & 0.2 & 0.3 & 0.4 & 0.5 & 0.6\end{array}$ 

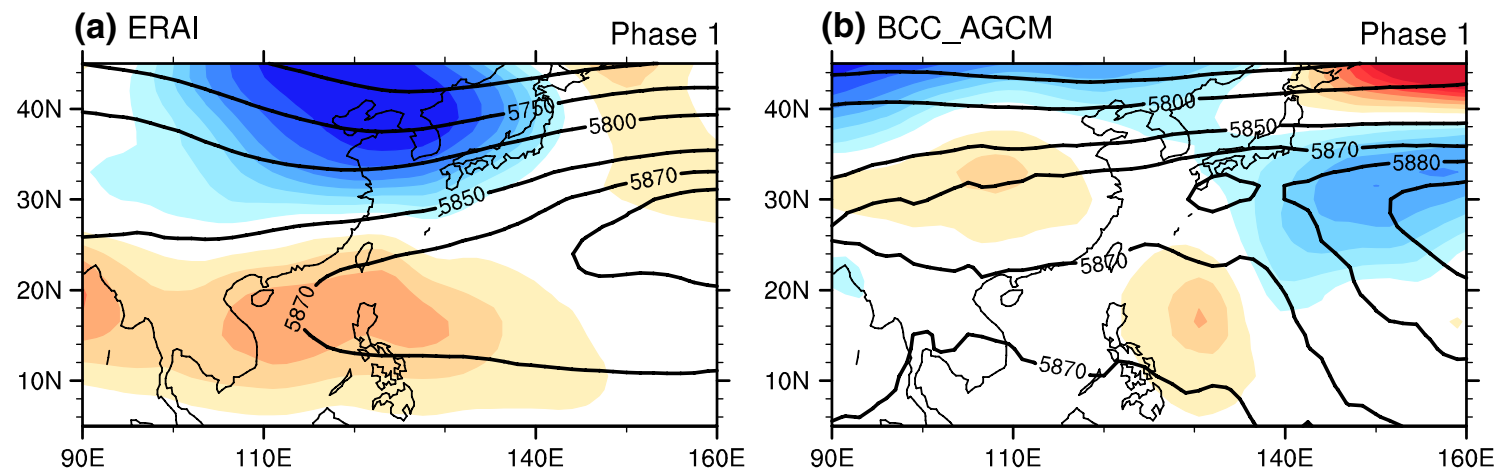

(c) ERAI

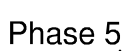

\section{(d) BCC_AGCM}

Phase 5

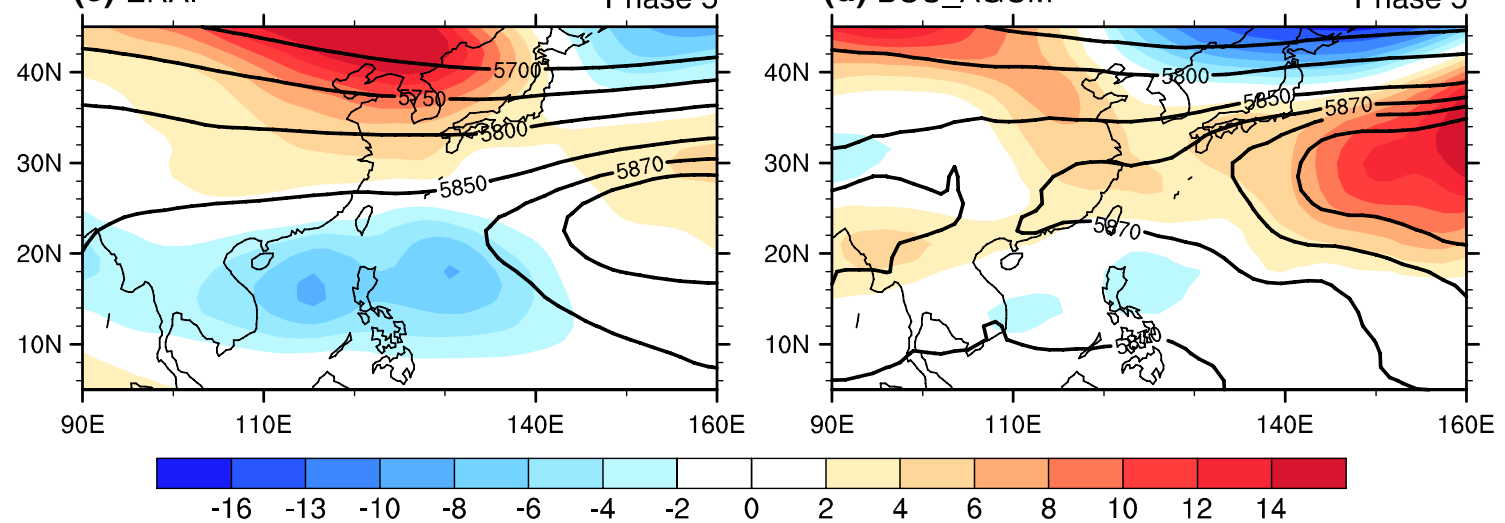

Fig. 10 Composites of filtered (shaded) and unfiltered (contour) $500 \mathrm{hPa}$ geopotential height for Phase 1 and 5 of BSISO events to compare modeled western Pacific subtropical high (right) with ERAInterim

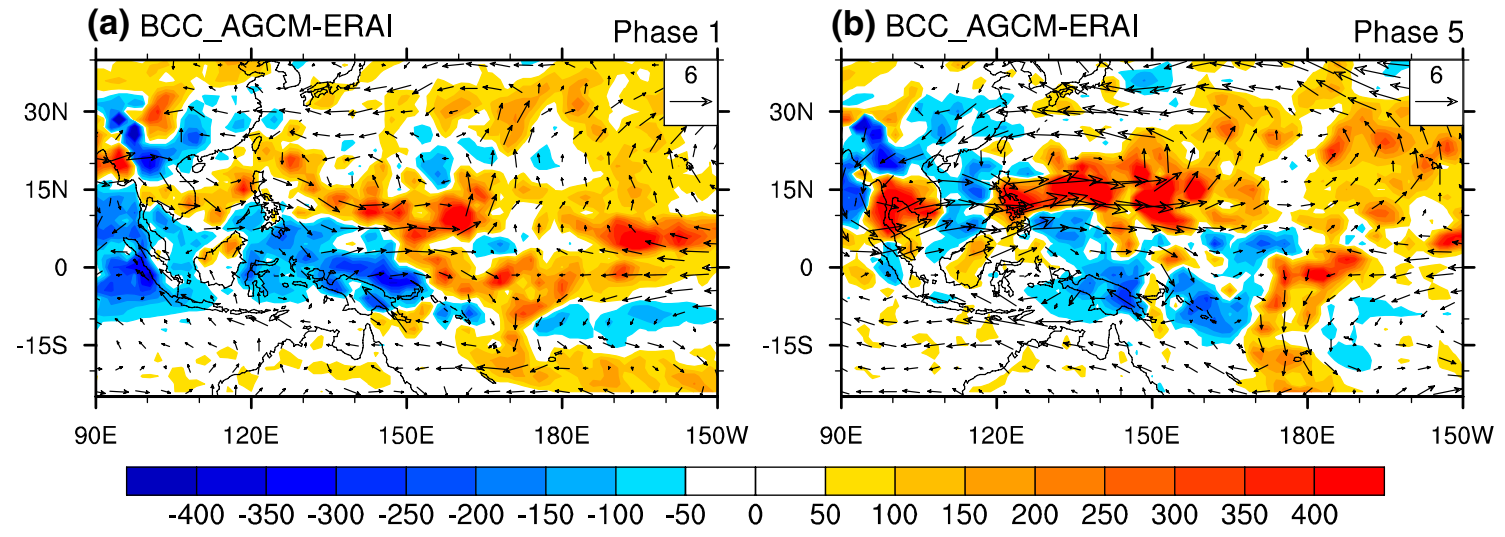

Fig. 11 Composites of model-ERAInterim difference of unfiltered diabatic heating (shaded, $\mathrm{W} \mathrm{m}^{-2}$ ) and non-divergent $850 \mathrm{hPa}$ winds $\left(\mathrm{m} \mathrm{s}{ }^{-1}\right.$ ) for Phase $1 \mathbf{a}$ and $5 \mathbf{b}$ to show model bias in diabatic heating as a result of seasonal mean precipitation errors

anomalies in upper troposphere responds to diabatic heating bias shown in Fig. 11 are opposite to those in the lower troposphere (figure omitted). These biases of circulation in both the low and upper troposphere imply a stronger vertical shear in zonal winds as shown in Fig. 1b, which also favors the northward shift of the ISO related rain belt (Wang and Xie 1997; Jiang and Li 2005). 


\section{Summary and discussion}

Climate models play an increasingly more important role in projecting future climate change as well as near term climate predictions. Faithful simulation of observed climate variability in addition to mean climate states will undoubtedly increase our confidence in modern climate models. The Beijing Climate Centre models have participated in the past two IPCC climate change assessment reports and will be contributing to the upcoming CMIP6. Intra-seasonal variability of the East Asia summer monsoon is of critical importance to regional climate as it is closely associated with seasonal drought, floods and water resources. This paper provides a systematic evaluation of the boreal summer intra-seasonal oscillation simulated by the latest version of the BCC climate model BCC_AGCM2.2 using an ensemble of 10 year atmospheric model simulations forced by observed sea surface temperatures. The evaluation includes mean states, power spectrum, CEOF analysis, phase relationship, composite analysis of horizontal and vertical structures as well as the intra-seasonal variability of the WNPSH and its role in model bias of the simulated BSISOs.

Overall, the BCC_AGCM2.2 model can reasonably simulates the seasonal mean-state of the atmosphere during the EA-WNP monsoon. However, some notable discrepancies are found in the simulated summer mean rainfall and its annual cycle. The model overestimates the seasonal mean precipitation over the WNP region, but underestimates the precipitation over the EA region, as well as the modeled onset of the South China Sea monsoon rainfall is earlier about 1 month than the observation. The model spatio-temporal features of the BSISO are examined in terms of power spectra, propagation features, leading EOF modes, horizontal and vertical structures. While the simulated power spectrum and variance as well as the spatial patterns of the leading EOF modes are close to the observations, the BSISO magnitude is overestimated over the WNP but underestimated over the EASM region as a result of mean precipitation errors. The large-scale convective organization is well captured but the tilted rain-band structure is not consistent with the observation. The model is also capable of correctly simulating the observed phase relationship between convection and cloud hydrometeors and the dynamics and thermodynamics of northward propagation. However, the model tends to generate unrealistic strong diabatic heating and convective instability towards the lower troposphere, which indicates the occurrence of stronger ISO activities from shallow convections.

One particular inconsistency between the modeled and observed BSISOs is that in the model BSISO signals propagate about $5^{\circ}$ further north than observation shows. This links up with unrealistic moisture-convection feedbacks in the model resulting from erroneous moisture transport in boundary layer driven by a biased northwestward extension of the WNPSH. Further analysis reveals that it is the unrealistically strong convective heating over the WNP region associated with mean precipitation errors forces a Gilltype response that pushes the WNPSH northwestward. The mean precipitation errors may be linked with the cumulus and cloud parameterization in the model. This illustrates the importance of background state of WNP summer convective on the northward propagating BSISOs over the EAWNP region.

It needs to be noted that we only address the possible role of wet precipitation bias over the WNP region affects the BSISOs through the modulation of summertime WNPSH and not vice versa. The results indicate that diabatic heating plays a reinforcing role in the westward and intensified WNPSH, which are consistent with some previous studies (Zhou et al. 2009; Matsumura et al. 2015). However, some studies have found the WNPSH bias is also related to other bias in BCC_AGCM2.2, such as the wet bias over the Indian summer monsoon region, weak walker circulation, and lower air temperature over the Tibetan Plateau (Wu et al. 2010; Kan et al. 2015). These biases may in turn influence the monsoon precipitation and associated BSISO and need to be verified by numerical experiments.

Another noteworthy bias is the lack of the associated eastward propagation of the northwest-southeast tilted convection front across the Maritime Continent (Fig. 6). While this indicates that the model can capture the northward propagating BSISO independent of the east propagating MJO, further evaluation of model in simulating the MJO and BSISO of Indian summer monsoon is needed and will be reported in the near future.

In this study, the results based on atmosphere only simulations provide some confidence on the model's capability of capturing the gross features of the observed BSISOs over the EA-WNP region. While coupling to ocean model can result in SST biases that compromise the mean state and the associated BSISO simulation, inclusion of air-sea coupling could lead to significant differences in terms of the large-scale organization, amplitude and propagation $(\mathrm{Fu}$ and Wang 2004; Chou and Hsueh 2010; Fang et al. 2013). One main issue we have highlighted in this paper is the sensitivity of convection parameterizations. It is, therefore, desirable to compare such evaluations in different models to investigate the sensitivity of model resolution, convective parameterization and air-sea interaction.

Acknowledgments This work was supported by National Basic Research Program of China (973 Program) (Grant No. 2015CB453200), the National Natural Science Foundation of China (Grant Nos. 41105069 and 41305057), and the Special Program for China Meteorology Trade (Grant No. GYHY201306003). Met Office staff were supported by the Joint UK DECC/DEFRA Met Office 
Hadley Centre Climate Programme (GA01101) and the UK-China Research and Innovation Partnership Fund through the Met Office Climate Science for Service Partnership (CSSP) China as part of the Newton Fund. We are grateful to the anonymous reviewers for their useful suggestions and comments.

Open Access This article is distributed under the terms of the Creative Commons Attribution 4.0 International License (http://creativecommons.org/licenses/by/4.0/), which permits unrestricted use, distribution, and reproduction in any medium, provided you give appropriate credit to the original author(s) and the source, provide a link to the Creative Commons license, and indicate if changes were made.

\section{References}

Abhik S, Halder H, Mukhopadhyay P, Jiang X, Goswami BN (2013) A possible new mechanism for northward propagation of boreal summer intra-seasonal oscillations based on TRMM and MERRA reanalysis. Clim Dyn 40:1611-1624. doi:10.1007/ S00382-012-1425-X

Ajayamohan RS, Goswami BN (2007) Dependence of simulation of boreal summer tropical intra-seasonal oscillations on the simulation of seasonal mean. J Atmos Sci 64:460-478. doi:10.1175/ JAS3844.1

Benedict JJ, Maloney ED, Sobel AH, Frierson DM, Donner LJ (2013) Tropical intra-seasonal variability in version 3 of the GFDL atmosphere model. J Clim 26:426-449. doi:10.1175/ JCLI-D-12-00103.1

Berrisford P, Dee D, Fielding K, Fuentes M, Kallberg P, Kobayashi S, Uppala S (2009) The ERA-interim archive. ECMWF Tech Rep 1:16

Chattopadhyay R, Goswami BN, Sahai AK, Fraedrich K (2009) Role of stratiform rainfall in modifying the northward propagation of monsoon intra-seasonal oscillation. J Geophys Res 114:D19114. doi:10.1029/2009JD011869

Chen TC, Murakami M (1988) The 30-50-day variation of convective activity over the western Pacific Ocean with emphasis on the northwestern region. Mon Weather Rev 116:892-906

Chou C, Hsueh YC (2010) Mechanisms of Northward-Propagating Intra-seasonal Oscillation-a comparison between the Indian Ocean and the Western North Pacific. J Clim 23:6624-6640. doi: 10.1175/2010JCLI3596.1

Collins WD, Rasch PJ, Boville BA, Hack JJ, McCaa JR, Williamson DL, Briegleb BP, Bitz CM, Lin SJ, Zhang M (2006) The formulation and atmospheric simulation of the community atmosphere model version 3 (CAM3). J Clim 19:2144-2161. doi:10.1175/JCLI3760

Dee DP et al (2011) The ERA-interim reanalysis: configuration and performance of the data assimilation system. Quart J Roy Meteor Soc 137:553-597

Demott CA, Stan C, Randall DA, Branson MD (2014) Intra-seasonal variability in coupled GCMs: the roles of ocean feedbacks and model physics. J Clim 27:4970-4995. doi:10.1175/ JCLI-D-13-00760.1

Ding Y, Chan JCL (2005) The East Asian summer monsoon: an overview. Meteorol Atmos Phys 89:117-142. doi:10.1007/ s00703-005-0125-z

Duchon CE (1979) Lanczos filtering in one and two dimensions. J Appl Meteorol 18:1016-1022

Fang YJ, Zhang YC, Huang AN, Li B (2013) Seasonal and intra-seasonal variations of East Asian summer monsoon precipitation simulated by a regional air-sea coupled model. Adv Atmos Sci 30(2):315-329. doi:10.1007/s00376-012-1241-6
Fu X, Wang B (2004) The boreal-summer intra-seasonal oscillations simulated in a hybrid coupled atmosphere-ocean model. Mon Weather Rev 132:2628-2649

Fu X, Wang B, Tao L (2006) Satellite data reveal the 3-D moisture structure of tropical intra-seasonal oscillation and its coupling with underlying ocean. Geophys Res Lett 33:L03705. doi:10.1 029/2005GL025074

Gill AE (1980) Some simple solutions for heat-induced tropical circulation. Q J Roy Meteorol Soc 106:447-462

Hsu HH, Weng CH (2001) Northwestward propagation of the intra-seasonal oscillation in the western North Pacific during the boreal summer: structure and mechanism. J Clim $14: 3834-3850$

Hu WT, Duan AM, Wu GX (2013) Performance of FGOALS-s2 in simulating intra-seasonal oscillation over the South Asian monsoon region. Adv Atmos Sci 30(3):607-620. doi:10.1007/ s00376-013-2156-6

Huffman GJ, Adler RF, Bolvin DT, Gu G, Nelkin EJ, Bowman KP, Hong Y, Stocker EF, Wolff DB (2007) The TRMM multisatellite precipitation analysis (TMPA): quasi-global, multiyear, combined-sensor precipitation estimates at fine scales. J Hydrometeorol 8:38-55

Jiang X, Li T (2005) Reinitiation of the Boreal Summer Intra-seasonal Oscillation in the Tropical Indian Ocean. J Clim 18:3777-3795

Jiang X, Li T, Wang B (2004) Structures and mechanisms of the northward-propagating boreal summer intra-seasonal oscillation. J Clim 17:1022-1039

Jiang X, Waliser DE, Li JL, Woods C (2011) Vertical cloud structures of the boreal summer intra-seasonal variability based on CloudSat observations and ERA-interim reanalysis. Clim Dyn 36:2219-2232. doi:10.1007/s00382-010-0853-8

Kan M, Huang A, Zhao Y, Zhou Y, Yang B (2015) Wu H (2015) Evaluation of the summer precipitation over China simulated by BCC_CSM model with different horizontal resolutions during the recent half century. J Geophys Res Atmos 120:4657-4670. doi:10.1002/2015JD023131

Lau KM, Chan PH (1986) Aspects of the 40-50 day oscillation during the northern summer as inferred from outgoing longwave radiation. Mon Weather Rev 114:1354-1367

Li C, Wu P (1990) An observational study of 30-50 day atmospheric oscillation. Part 1: structure and propagation. Adv Atmos Sci. doi:10.1007/BF03179762

Liebmann B, Smith CA (1996) Description of a complete (interpolated) outgoing longwave radiation dataset. Bull Am Meteorol Soc 77:1275-1277

Lin $H$ (2012) Monitoring and predicting the intra-seasonal variability of the East Asian-Western North Pacific Summer Monsoon. Mon Weather Rev 141:1124-1138. doi:10.1175/MWR-D-12-00087.1

Lin JL et al (2006) Tropical intra-seasonal variability in 14 IPCC AR4 climate models. Part I: convective signals. J Clim 19:2665-2690. doi:10.1175/JCLI3735.1

Lin JL, Weickman KM, Kiladis GN, Mapes BE, Schubert SD, Suarez MJ, Bacmeister JT, Lee MI (2008) Subseasonal variability associated with Asian summer monsoon simulated by 14 IPCC AR4 coupled GCMs. J Clim 21:4541-4567

Madden RA, Julian PR (1972) Description of global-scale circulation cells in the tropics with a $40-50$ day period. J Atmos Sci 29:1109-1123

Mao JY, Sun Z, Wu GX (2010) 20-50-day oscillation of summer Yangtze rainfall in response to intra-seasonal variations in the subtropical high over the western North Pacific and South China Sea. Clim Dyn 34:747-761. doi:10.1007/s00382-009-0628-2

Matsumura S, Sugimoto S, Sato T (2015) Recent Intensification of the Western Pacific Subtropical High Associated with the East Asian Summer Monsoon. J Clim 28:2873-2883. doi:10.1175/ JCLI-D-14-00569.1 
Rayner NA, Parker DE, Horton EB, Folland CK, Alexander LV, Rowell DP, Kent EC, Kaplan A (2003) Global analyses of sea surface temperature, sea ice, and night marine air temperature since the late nineteenth century. J Geophys Res 108(D14):4407. doi:10.1 029/2002JD002670

Ren X, Yang XQ, Sun X (2013) Zonal oscillation of western pacific subtropical high and subseasonal SST variations during yangtze persistent heavy rainfall events. J Clim 26:8929-8946. doi:10.1175/JCLI-D-12-00861.1

Rodwell MJ, Hoskins BJ (2001) Subtropical anticyclones and summer monsoons. J Clim 14:3192-3211

Sabeerali CT, Dandi AR, Dhakate A, Salunke K, Mahapatra S, Rao SA (2013) Simulation of boreal summer intra-seasonal oscillations in the latest CMIP5 coupled GCMs. J Geophys Res Atmos 118:4401-4420. doi:10.1002/jgrd.50403

Seo KH, Schemm JKE, Wang W, Kumar A (2007) The boreal summer intra-seasonal oscillation simulated in the NCEP Climate Forecast System: the effect of sea surface temperature. Mon Weather Rev 135:1807-1827. doi:10.1175/MWR3369.1

Shukla RP (2014) The dominant intra-seasonal mode of intra-seasonal South Asian summer monsoon. J Geophys Res Atmos 119:635-651. doi:10.1002/2013JD020335

Sooraj KP, Seo KH (2013) Boreal summer intra-seasonal variability simulated in the NCEP climate forecast system: insights from moist static energy budget and sensitivity to convective moistening. Clim Dyn 41:1569-1594. doi:10.1007/s00382-012-1631-6

Sperber KR, Annamalai H (2008) Coupled model simulations of boreal summer intra-seasonal (30-50 day) variability, Part 1: systematic errors and caution on use of metrics. Clim Dyn 31:345-372. doi:10.1007/s00382-008-0367-9

Waliser DE et al (2003) AGCM simulations of intra-seasonal variabilitv associated with the Asian Summer monsoon. Clim Dyn 21:423-446. doi:10.1007/s00382-003-0337-1

Wang B, Xie X (1997) A model for the boreal summer intra-seasonal oscillation. J Atmos Sci 54:72-86

Wu P (1993) Nonlinear resonance and instability of planetary waves and low-frequency variability in the atmosphere. J Atmos Sci 50:3590-3607
Wu T (2012) A mass-flux cumulus parameterization scheme for largescale models: description and test with observations. Clim Dyn 38:725-744. doi:10.1007/s00382-011-0995-3

Wu P, Li C (1990) The 10-20 day oscillation in the atmosphere. Special issue of collected papers. Chinese Journal of Atmospheric Sciences. Science Press, Beijing, pp 149-159 (in Chinese)

Wu T, Wu GX (2004) An empirical formula to compute snow cover fraction in GCMs. Adv Atmos Sci 21:529-535

Wu T, Yu R, Zhang F (2008) A modified dynamic framework for atmospheric spectral model and its application. J Atmos Sci 65:2235-2253. doi:10.1175/2007JAS2514.1

Wu T, Yu R, Zhang F, Wang Z, Dong M, Wang L, Jin X, Chen D, Li L (2010) The Beijing Climate Center atmospheric general circulation model: description and its performance for the present-day climate. Clim Dyn 34:149-150. doi:10.1007/s00382-008-0487-2

Yanai M, Esbensen S, Chu JH (1973) Determination of bulk properties of tropical cloud clusters from large-scale heat and moisture budgets. J Atmos Sci 30:611-627

Yang J, Wang B, Wang B, Li LJ (2009) The East Asia-western North Pacific boreal summer intra-seasonal oscillation simulated in GAMIL 1.1.1. Adv Atmos Sci 26(3):480-492

Zhang MH, Geller MA (1994) Selective excitation of tropical atmospheric waves in wave-CISK: Effect of vertical wind shear. J Atmos Sci 51:353-368

Zhao CB, Zhou TJ, Song LC, Ren HL (2014) The boreal summer intra-seasonal oscillation simulated by four Chinese AGCMs participating in the CMIP5 project. Adv Atmos Sci 31(5):11671180. doi:10.1007/s00376-014-3211-7

Zhou T, Yu R, Zhang J, Drange H, Cassou C, Deser C, Hodson DLR, Sanchez-Gomez E, Li J, Keenlyside N, Xin X, Okumura Y (2009) Why the western Pacific subtropical high has extended westward since the late 1970s. J Clim 22:2199-2215. doi:10.117 5/2008JCLI2527.1 